\title{
LA ACTUALIDAD DE FRANCISCO SUÁREZ EN LA EDAD DE PLATA ESPAÑOLA"
}

\author{
DELIA MANZANERO \\ Universidad Rey Juan Carlos de Madrid
}

\begin{abstract}
RESUMEN: El presente artículo expone la revitalización de los temas y la metodología jurídica de los clásicos hispanos de la Escuela del Derecho Natural, que tiene en Francisco Suárez a uno de sus más excelsos representantes, y que se despliega durante el último tercio del siglo XIX y las primeras décadas del XX. Para tratar de esta etapa de revitalización de las tesis iusnaturalistas, subrayaremos las concomitancias existentes entre los krausistas decimonónicos españoles y las que vivieron los clásicos españoles, para llegar hasta lo que consideramos un eslabón imprescindible en esta fase de recuperación de la doctrina del Derecho Natural suareciana: la enjundiosa lectura que hace el iusfilósofo Luis Recaséns Siches de la obra jurídica de Francisco Suárez, donde se aprecia la fecunda inspiración contenida en la obra del gran clásico español y se desarrolla una concepción iusnaturalista depurada y a la altura de nuestro tiempo.
\end{abstract}

PALABRAS CLAVE: iusnaturalismo; corpus mysticum; Krausismo; Suárez; Recaséns.

\section{The validity of Francisco Suarez's Philosophy of Law in the Spanish Silver Age}

ABSTRACT: The present article seeks to present the revitalization that occurs during the Spanish Silver Age of the topics and the juridical methodology of the Spanish Natural Law Classics, which has in the Jesuit philosopher and theologian Francisco Suarez, one of the prime leading figures. In order to deal with this stage of revitalization of the iusnaturalist Suarezian theses and their repercussions in the Spanish Natural Law Philosophy that unfolds during the last third of the nineteenth century and the first decades of the twentieth century, we will emphasize the concomitances between the nineteenth-century Krausists and those who lived the magni Hispani, to reach what we consider to be an indispensable link in this phase of recovery of the Natural Law theory: the substantial reading on Francisco Suarez's legal work made by the iusphilosopher Recasens Siches, where we can appreciate the suggestive inspiration contained in the work of our great Spanish classic and where it develops a renew iusnaturalist conception appropriate for our present time.

KEY WORDS: Iusnaturalism; corpus mysticum; Krausism; Suarez; Recasens.

\section{INTRODUCCIÓN}

Francisco Suárez ha sido una de las mayores influencias en el pensamiento jurídico de la Edad de Plata de la cultura española, sobre todo, en la obra de autores como Recaséns Siches, quien reconoce en Suárez a un maestro y quien acomete con formidable éxito la labor de recuperar su obra; por ello nos detendremos a explicar su pensamiento y su repercusión para el iusnaturalismo

Esta investigación se ha realizado en el marco del proyecto de investigación de la Universidad Pontificia Comillas: «Krause y el krausismo del sexenio democrático» (Proyecto de investigación I+D+i: HAR2016-79448-P, 2016-2019), financiado por el Ministerio de Economía y Competitividad. Asimismo, este estudio se inscribe dentro de una Ayuda Juan de la Cierva - Formación Posdoctoral adscrita a la Universidad Rey Juan Carlos de Madrid, financiada por el Ministerio de Economía y Competitividad (FPDI-2013-17242). 
hispano, así como en los beneficios del desarrollo y proyección de la doctrina suareciana en la España decimonónica y de principios del siglo XX, de la cual fue responsable el propio Recaséns, reconocido experto en la filosofía jurídica de Francisco Suárez, sobre quien hizo su tesis doctoral ${ }^{1}$.

En esta primera parte introductoria, nos ha parecido conveniente consagrar unas breves líneas al que fue maestro de varias generaciones de filósofos del Derecho en España y en tantas otras latitudes, al iusfilósofo hispanoguatemalteco Luis Recaséns Siches, considerado como el gran reformador de la Filosofía del Derecho en España y «el mayor representante del exilio iusfilosófico» español ${ }^{2}$. Recaséns forma parte también del grupo de los denominados sociólogos sin sociedad - en la afortunada expresión acuñada por Arboleya ${ }^{3}$-, para referirse a esa constelación de profesores, a esa España peregrina $a^{4}$ que tuvo que exiliarse como consecuencia de la derrota de la II República en la Guerra Civil y el comienzo del franquismo, pero que, a pesar de todo, consiguió desarrollar una relevante y fecunda obra en el exilio. Dentro de esa amplia y variada generación, quizá sea Luis Recaséns Siches el único de nuestros intelectuales exiliados cuya dedicación a la filosofía del Derecho constituyó su profesión; con gran éxito, además, y con proyección internacional, pues Recaséns ha sido considerado como la cabeza dirigente de la filosofía del derecho española moderna y como uno de los más ilustres iusfilósofos de habla castellana hasta hace muy poco, a pesar de que las innovadoras ideas de este insigne catedrático de Filosofía del Derecho fueron borradas durante largo tiempo y sólo alcanzaron su merecido reconocimiento más tarde.

Hecha esta breve pero conveniente presentación, entremos ya a presentar algunos aspectos clave del sistema de la filosofía jurídica de Francisco Suárez que Recaséns Siches recupera en su obra, y cómo esto se tradujo en un amplio y profundo programa de reformas jurídicas y sociológicas que se dio durante el periodo de la Edad de Plata española.

1 Recaséns Siches, L., La Filosofía del Derecho de Francisco Suárez, con un estudio previo sobre sus antecedentes en la patrística y en la escolástica, Barcelona, $1^{\mathrm{a}}$ edición 1927, cita por la $2^{\mathrm{a}}$ edición corregida y aumentada, México, editorial jus, 1947.

2 De hecho, se ha llegado incluso a tomar el año de su fallecimiento para marcar el cierre del periodo de muchos estudios dedicados a investigar sobre el exilio iusfilosófico español, un exilio que empieza como es bien sabido en el año 1936 y que se cierra en muchos estudios con la fecha simbólica del fallecimiento de Recaséns en México el año 1977. Rivaya García, B., «El exilio iusfilosófico español (1936-1977/1981)», ponencia del I Congreso de Filosofía del Derecho para el mundo latino, Alicante, 26-28 de mayo de 2016, p. 1 (Fecha de consulta: 10-12-2016).

iusfilosofiamundolatino.ua.es/download/RIVAYA $\% 20$ GARCI\%CC\%81 A, $\% 20$ Benjami\%CC $\% 81$ n $\% 20-\% 20$ El\%20xilio\%20iusfiloso $\%$ CC $\% 81$ fico $\% 20$ espan $\%$ CC $\% 83$ ol $\% 20$ (1936-1977:1981).pdf

3 Arboleya, E. Gómez, «Sociología en España», en: Giner, S., y Moreno, L., Sociología en España, Madrid: CSIC, 1990 (1. ${ }^{a}$ ed. 1958).

4 SÁnchez Cuervo, Antolín, "¿Saber sin poder? El ethos universitario según los filósofos del exilio republicano español del 39», Isegoría, No 52 (2015):205-220, (p. 208) doi:10.3989/ isegoria.2015.052.09 
Empecemos pues repasando algunas de esas valiosas doctrinas suarecianas que se reformulan y son planteadas en la obra de Recaséns Siches, para ver su proyección en el proyecto de renovación jurídico-social que ocupa la Edad de Plata española ${ }^{5}$, a fin de calibrar mejor su relevancia para los desafíos sociales y políticos contemporáneos. Entre los logros de los proyectos culturales y políticos que Recaséns Siches recupera de la obra de Suárez encontramos: i). la necesidad creciente de que la estimativa jurídica iusnaturalista tuviera en cuenta los conocimientos sociológicos, esto es, la acentuación del sentido histórico para los ideales jurídicos en armonía con las realidades sociales concretas; ii). la convicción de que la Ética es el motor que anima la vida jurídico-social y su fe optimista en la razón; algo que Recaséns había aprendido también del krauso-institucionismo español ${ }^{6}$; iii). de ahí se deriva, en última instancia, su afirmación de la dignidad de la persona humana como supremo valor jurídico, y la autonomía ética de la persona a la que dota de un valor jurídico, tesis que han cumplido un importante papel en la génesis y evolución de los derechos humanos y que son, asimismo, denominador común del pensamiento iusnaturalista de nuestros días; iv) su fe inconmovible en un Derecho internacional, una fe que mantiene Recaséns aun en medio de la guerra mundial y tras haber sufrido en primera persona las consecuencias de una guerra civil que le expulsó al exilio ${ }^{7}$; v). por último, pero no menos importante, el repudio a la lógica formal físico-matemática, la cual debía ser reemplazada por lo que Recaséns denominó como el «logos de lo razonable», en virtud del cual, se atribuía preeminencia a la conciencia del juez sobre la regla jurídica. De ahí extrae Recaséns su relevante teoría de la interpretación del Derecho a través del concepto clásico de la Epiqueya suareciana.

Estas serían las líneas generales en que pueden resumirse algunas de sus principales aportaciones y donde más claramente se deja sentir el moderno pensamiento de Francisco Suárez. Vemos pues cómo, desde sus componentes sociológicos y jurídicos, la obra de Recaséns fue una filosofía especialmente adecuada para diseñar estrategias reformadoras frente a lo que representaría el conservadurismo cultural y el peso de la neoescolástica entre nosotros. En efecto, esta es una de las virtudes de la filosofía de Recaséns, su esperanza en la racionalidad política y su énfasis en la educación, la

5 «En lo tocante a la filosofía jurídica, al tiempo de la segunda República se le puede denominar Edad de Plata; o quizás mejor al período que va de 1929 al inicio de la guerra civil». Gil CREMAdes, J. J. «Filosofía del Derecho y compromiso político: Alfredo Mendizábal (1897-1981)», Anuario de filosofía del derecho, No 4, 1987, pp. 563-590 (p. 564).

6 Recaséns Siches, L., Panorama del pensamiento jurídico en el siglo XX, México, Editorial

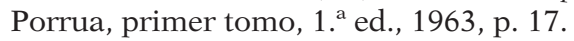

7 «se ve que existe una necesidad de deber ser, de aceptar esa norma, ya que sin ella no habría posibilidad de mantener la Comunidad internacional, la cual es, como Vitoria y Suárez mostraron y Kant y el moderno Derecho internacional reconocen, una necesidad cultural, y, por tanto, fuente de un deber jurídico». RADBRUCH, G., Introducción a la ciencia del Derecho, Traducción de Luis Recaséns Siches, Prólogo de Fernando de los Ríos, Edit. Revista de Derecho Privado, Madrid, 1930, p. XII. del prólogo de Fernando de los Ríos. 
cual fue sin duda una herramienta eficaz para la lucha abierta contra los totalitarismos de su época.

Seguidamente expondremos unas consideraciones sobre algunas de las notas comunes al iusnaturalismo de Recaséns, que comparte, por cierto, no sólo con Francisco Suárez, sino con otros intelectuales españoles cuya obra conoce muy bien y con quienes hace escuela común.

\section{La encarnación de la doctrina de Francisco Suárez en la teoría del logos DE LO RAZONABLE DE ReCASÉNS SicheS}

Es interesante constatar cómo, detrás de sus críticas al formalismo jurídico y de su posicionamiento intelectual de plantear las relaciones entre el Derecho y la Moral, resulta fácil reconocer que, junto con la nada desdeñable influencia de la élite del pensamiento europeo de aquél entonces ${ }^{8}$, Recaséns encontró paradójicamente la mayor fuente de inspiración para confeccionar su doctrina en España, ni más ni menos que en los clásicos hispanos del Derecho Natural desde la Escuela de Salamanca en la figura de Francisco Suárez- hasta la Edad de Plata Española — sobre todo en los iusnaturalistas del krausismo español, a los que Recaséns consideró como los principales protagonistas del primer renacimiento del iusnaturalismo en España a finales del siglo XIX, en autores como Giner, Posada y Costa, quienes defienden un concepto de Derecho Natural que él encontró muy interesante y de gran utilidad por su vigencia y actualidad para nuestros días.

Ciertamente, en el núcleo doctrinal de la filosofía del derecho de Recaséns hallamos la encarnación viva del espíritu de Suárez. Sobre la relevancia de los estudios de los clásicos españoles y su utilidad para una renovación y revitalización de las tesis más sólidas y consistentes de la doctrina suareciana del Derecho Natural, se pronunciaba Recasens Siches en esta excelente obra suya dedicada a La Filosofía del Derecho de Francisco Suárez.

8 La obra de Recaséns Siches es fruto del periplo de estudios en el extranjero marcado por sus tres estancias becadas: en Berlín al lado de Stammler, en Viena con Kelsen, y sobre todo, la investigación realizada en Roma con Del Vecchio, que le hace olvidar un poco la influencia del idealismo alemán para cimentar su obra en la realidad social. A su regreso a España a finales del año 1927 es cuando Recaséns empieza a difundir en nuestro país todo lo que había aprendido en su formación académica por Europa, y lo que quizá le convierte en uno de nuestros mejores historiadores de Filosofía del Derecho. Estando ya en España, decide Recaséns recuperar la labor de Stammler de superar el positivismo doctrinario, y de continuar la tarea de revitalización del sentido iusnaturalista que aprendió durante su investigación predoctoral en Francisco Suárez, y en Roma con Del Vecchio; un iusnaturalismo cuyo sentido - según el propio Recaséns- se había perdido durante el siglo XIX.

9 Recaséns Siches, L., La Filosofía del Derecho de Francisco Suárez, con un estudio previo sobre sus antecedentes en la patrística y en la escolástica, Barcelona, $1^{\text {a }}$ edición 1927, cita por la $2^{\mathrm{a}}$ edición corregida y aumentada, México, editorial jus, 1947, p. 113. 
De Suárez retoma Recaséns el importante concepto de la epiqueya (como interpretación y adaptación de la ley a los casos concretos), que le permite fundamentar la que quizá sea su mayor joya doctrinaria y su más novedosa aportación a la Filosofía del Derecho: su teoría del logos de lo razonable ${ }^{10}$.

La doctrina de Francisco Suárez sobre el problema de la interpretación judicial y la invariabilidad que corresponda a la ley natural, así como el sentido y alcance que dicho carácter tenga, constituye uno de los luminosos momentos de la historia de la filosofía del derecho que es retomado y replanteado por la filosofía jurídica de Recaséns Siches: el que versa sobre la amplitud del derecho natural, su rigidez o flexibilidad al ser interpretado, y la relación que guarda con los contenidos empíricos en la historia y su aplicabilidad a casos concretos.

Consideramos que sin la reflexión de Suárez sobre el enjundioso concepto de la Epiqueya ${ }^{11}$, no sería posible comprender esta teoría nuclear en la obra de Recaséns sobre el logos de lo razonable, donde se relativiza el valor jurídico de las palabras de la ley, cuando por los cambios sociales o históricos, resultan perjudiciales al orden o al bien común.

En definitiva, como trataremos de mostrar, a la interpretación por equidad suareciana, afinando y actualizando más algunas ideas, es a lo que Recaséns llama interpretación mediante la lógica de lo razonable. Ambos pensadores invocan el concepto y aplicación de la epiqueya, según el cual se reconoce no sólo la posibilidad, sino la necesidad del método de la equidad (epiqueya) como corrección e interpretación de los principios del derecho natural para la adaptación de sus derivaciones a casos concretos y a las circunstancias históricas; todo lo cual implicaba una corrección del ideal a través de unas bases más realistas o históricas porque, —en palabras de Francisco Suárez-, «la ley natural, en algunos de sus preceptos más alejados de los primeros principios, versa sobre materias mudables que en muchos casos pueden cambiar, según dijo Aristóteles: luego en esas materias es también necesaria la epiqueya, pues, en otro caso, muchas veces la ley natural sería injusta» ${ }^{12}$.

Suárez sostiene expresamente que el derecho natural es en sí inmutable, sin embargo, ello no impide que un sector de sus preceptos puedan experimentar modificaciones en sus contenidos, mas no porque los principios racionales varíen, sino porque, transformándose la materia social a que se aplican, cambia también el precepto, lo cual está previsto ya en el sentido del mismo del Derecho.

«el conocido ejemplo de San Agustín de que, así como la medicina da unas recetas para los enfermos y otras para los sanos, unas para los fuertes y otras

10 Vid. Recaséns Siches, L., Tratado General de Filosofía del Derecho, 19. e edición, editorial Porrúa, México, 2008 (primera edición, 1959), p. 16.

11 Esto es: «el problema de cómo ha de actuar el juez cuando la aplicación de una norma, en apariencia vigente, al problema singular sometido a su conocimiento, llevaría a un resultado notoriamente injusto». Recaséns Siches, L., Panorama del pensamiento jurídico en el siglo XX, México, Editorial Porrua, primer tomo, 1. ${ }^{\mathrm{a}}$ ed., 1963, p. 15.

12 Suárez, F., De Legibus, op. cit., Volumen I, libro II, capt XV, p. 173. 
para los débiles, y sin embargo no por eso las reglas de la medicina cambian en sí mismas, sino que se multiplican y ahora sirven unas y luego otras, así también el derecho natural, siendo él mismo, en tal ocasión manda una cosa y otra en otra, y ahora obliga y no antes o después — sin cambiar él— por razón del cambio de materia» ${ }^{13}$.

Esta corrección del Derecho se hace basándose en aspectos sociológicos y psicológicos, así como en principios de justicia, porque — sostiene Recaséns, siguiendo en esto de cerca a Suárez- no se debe tratar igualmente casos desiguales: por esto, la misma ley natural dispone que se practique la epiqueya, la equidad. Esto supone, en efecto, una labor interpretativa en el Derecho que revaloriza el papel de la racionalidad práctica como parámetro orientador de la interpretación jurídica, sobre la cual, se pronuncia Recaséns Siches para explicar su método de la lógica de lo razonable, de un logos más humano, contrario a la lógica racional pura de tipo matemático y a la teoría de la subsunción, pues Recaséns considera insuficiente la aplicación estricta de la norma a través de un procedimiento lógico de carácter eminentemente silogístico-deductivo ${ }^{14}$.

Por su parte, para Francisco Suárez el derecho legislado o positivo, aunque no deba apartarse de la ley natural, tiene un fin e idea informantes diferentes al Derecho Natural, el bien común, lo cual va a hacer que su Derecho positivo arraigue en una perspectiva más empírica e histórica, que conlleva el empleo de una metodología mucho más moderna.

La importancia de este principio de interpretación flexible del derecho que permite eximir al juez de la observancia literal o textual de una ley positiva con el propósito de ser fiel a su auténtico espíritu o sentido, tal y como viene recogido en la fórmula de la Epiqueya, es enorme, pues se reconoce que las cosas o las circunstancias pueden cambiar y que el hombre puede, en muchos casos, modelar las relaciones jurídicas, interpretándolas en forma razonable afirma Recaséns-, a la luz de su propósito evidente, de tal manera que, según cómo las estructure, así serán los preceptos naturales que reciban aplicación. Con otras palabras, más que leyes buenas, Recaséns lo que pedía era jueces rectos y humanos, en una línea de pensamiento que entroncaría con un enfoque judicialista que llega hasta nuestros días, según el cual, la garantía del Derecho se halla, no ya en una normatividad abstracta, sino en el ejemplo de los actos de justicia como conducta habitual y virtuosa.

Estas premisas implican una perspectiva más realista y sociológica de la interpretación del Derecho cuyo interés es crucial para comprender la filosofía del derecho de Recaséns, y cuya proyección puede apreciarse en la repercusión que ha tenido en determinados autores de la filosofía del derecho contemporánea que también entienden la teoría y la práctica del derecho como argumentación.

13 SuÁrez, F., De Legibus, op. cit., Volumen I, Libro II, capt. XIV, p. 158.

14 Recaséns Siches, L., Tratado General de Filosofía del Derecho, 19. ${ }^{\circ}$ edición, editorial Porrúa, México, 2008 (primera edición, 1959), p. 7. 
La actualidad de esta problemática nuclear en la filosofía jurídica de Recaséns puede vislumbrase también en autores contemporáneos, como la obra de anglosajones que participan del sistema del Common Law norteamericano donde se ha gestado una filosofía del derecho que presta mayor atención a la interpretación judicial; entre ellos se encuentra el juez Ronald Dworkin, quien mantiene que lo que nos lleva a considerar como jurídicos a los principios morales son razones de contenido, esto es, razones morales, y no criterios formales basados en la autoridad del Estado ${ }^{15}$. Con esta tesis, se está abriendo la puerta a formas deliberativas de justificación de las normas públicas bien interesantes donde la lógica de lo razonable tiene un papel fundamental. Esta idea de la racionalidad práctica desempeña una importante función para garantizar la adecuación de las decisiones judiciales a consecuencias socialmente deseables y racionalmente fundadas. Mediante el ejercicio de la racionalidad práctica los jueces tienden a apoyar sus decisiones en criterios universalizables; es decir, rebasan objetivos particulares para perseguir aquellos valores generalizados e institucionalizados en la práctica social, que legitiman la observancia del Derecho. Así lo expresa el propio Recaséns:

«Hay que advertir que precisamente en nuestros días va extendiéndose cada vez más y más la opinión de que las dos cumbres más en la historia del Derecho se hallan representadas por [...] los jueces del Common Law, particularmente en nuestros días. Son muchas las opiniones en este sentido; y como ejemplo, por cierto muy egregio y representativo, recordemos a Radbruch, quien en los últimos años de su vida dio testimonio de su creciente y fervoroso entusiasmo por el juez anglosajón. Y sucede que esta opinión se basa precisamente el hecho de que en esas dos realidades jurisprudenciales no se cayó en el nefasto prurito de un sistematismo, imposible en materia de los contenidos de la jurisprudencia, antes bien, por el contrario, se ha practicado la vía del pensamiento aporético, problemático o argumentativo» ${ }^{16}$.

Ciertamente la epiqueya suareciana evolucionó y adquirió un desarrollo mayor en la obra jurídica y social de Recaséns Siches, la cual se vio favorecida y enriquecida gracias a la metodología empírica de finales del siglo XIX, manifiesta en su labor, de un modo palmario, al proponer un término original claramente antiformalista y antiabstracto del Derecho que fue resultado de la conjunción de tres influjos, en principio distintos, pero no excluyentes: el de la escuela histórica, el de las modernas concepciones sociológicas, pero sobre todo, el de una concepción filosófica krausista del derecho de abolengo iusnaturalista en torno a la cual gira la obra de Recaséns. A esta última corriente filosófica del krausismo nos referiremos en la siguiente sección por su significado papel en la recuperación de la obra de Suárez.

15 Dworkin, R. M., La Filosofía del Derecho, Traducción de Javier Sáinz de los Terreros, México, Fondo de Cultura Económica, 1980.

16 Recaséns Siches, "Logos de lo humano, experiencia jurídica y derecho», Anuario de filosofía del derecho, no 11, 1964, pp. 11-44. (p. 22). 
3. La RESTauración de la filosofía JuRÍdica de SuÁREZ EN El KRAUSismo ESPaÑol

Con el fin de recordar cuáles fueron los autores que acometieron con mayor empuje y con más logrado éxito esta empresa de restauración de la filosofía jurídica de Francisco Suárez, y aquilatar bien el tipo de iusnaturalismo que exhiben, resulta inexcusable empezar refiriéndonos a un libro del propio Recaséns titulado Iusnaturalismos actuales comparados ${ }^{17}$. Nos gustaría abundar en los contenidos de este libro no solo por su valor como obra fundamental para los estudios de filosofía del derecho, sino porque en ella se representan las principales y diversas corrientes de iusnaturalismos con los que Recaséns dialoga y con las que él se identifica en mayor o menor medida.

Estimamos oportuno tomar como hilo expositivo esta obra de Recaséns para presentar cuál fue esa trayectoria del iusnaturalismo en España y cómo Francisco Suárez se inscribe en ella, a través de la revitalización de sus doctrinas en lo que Recaséns Siches denominó como la primera ola de renacimiento del Derecho Natural en España; una restauración de conceptos clave suarecianos que se produce fundamentalmente en el marco del iusnaturalismo krausista español, el cual ofrecía un iusnaturalismo de nuevo cuño que fue objeto de furibundas críticas y censuras por parte de sus detractores tradicionales y por ideólogos intransigentes ${ }^{18}$.

En este libro, empieza Recasens por constatar el hecho innegable del renacimiento del Derecho natural como superación de un positivismo y de un formalismo ahistórico y legalista que se había visto impotente para resolver los grandes problemas que sus propias consecuencias habían creado. En este feliz revival del Derecho natural, Recasens distingue dos momentos: un primer renacimiento del Derecho natural que se iniciaría a comienzos del siglo XX y un segundo renacimiento cuyo comienzo toma como punto de partida la segunda guerra mundial ${ }^{19}$.

17 Recaséns Siches, L., Iusnaturalismos actuales comparados, Madrid, Universidad de Madrid, Facultad de Derecho, Sección de Publicaciones, 1970, 142 págs.

18 Véase. VÁzouez-Romero, J. M., Tradicionales y moderados ante la difusión de la filosofía krausista en España, Publicaciones de la Universidad Pontificia Comillas, Unión Editorial, Colección del ILKM, Madrid, 1998, pp. 19-20. No solo los gerifaltes del krausismo tuvieron que hacer frente a un contexto adverso que estalla, como es bien conocido, en las dos cuestiones universitarias por las que fueron separados de sus cátedras; el propio Recaséns fue uno de esos catedráticos de filosofía del derecho que fueron depurados y enviados al exilio, de ahí que su trayectoria vital y académica se encuentre también muy ligada al devenir de la Filosofía del Derecho como ciencia en España, desde sus momentos de renacimiento a los momentos de recesión, ausencia e incluso exclusión del ámbito académico. Averiguar las razones de su promoción no es pues algo baladí, sino que responde y está ligado a la historia política y cultural de España.

19 Sobre este segundo renacimiento iusnaturalista que se produce a partir de mediados del cuarto decenio del siglo XX, véase: RECASÉns Siches, L., "Otra vez y con renovado vigor: Derecho Natural», Anales de la Cátedra Francisco Suárez, 50 (2016), 41-70. [1ª ed., No 5-6, 1965-1966, págs. 5-46]. 
Nos gustaría fijar nuestra atención en el primer renacimiento del Derecho Natural porque la propia obra de Recaséns se desarrolla, y no por casualidad, bajo la impronta institucionista, y porque su exposición nos ayudará a comprender mejor su doctrina.

El primer renacimiento del Derecho Natural al que se refiere Recaséns en su libro empieza a producirse sobre bases muy sólidas con una restauración de los temas de axiología jurídica, de los valores que fundamentan y justifican el Derecho; una tesis que ha sido predominante en las obras de Recaséns, pues, según expresa él mismo, si negamos el Derecho natural o la idea de la justicia, arruinamos los fundamentos del Derecho positivo convirtiendo y reduciendo a éste en un mero fenómeno de fuerza y coacción:

«Toda la interpretación está empapada de una serie de juicios de valor. Toda norma jurídica es una estructura de finalidad, la cual responde a una valoración positiva, la valoración sobre la cual se ha establecido la norma. Ahora bien, las finalidades y las valoraciones están regidas por una lógica especial, por una particular provincia del logos, que juega un papel decisivo en la interpretación $»^{20}$.

No hay pues un derecho neutral, sino que la propia norma positiva constituye ya la expresión de un juicio de valor. De hecho, afirma Recaséns, la normatividad del Derecho positivo carecería en absoluto de sentido si no estuviese referida a un juicio de valor que es precisamente lo que la inspira. Con otras palabras, sin valoraciones no cabría la existencia del Derecho positivo. Por esta razón, concluye Recasens, la negación positivista a aceptar la existencia de dichos valores contiene un $a b s u r d o^{21}$. Cabe decir incluso que si un concepto de Derecho y de instituciones coercitivas no fuera capaz de mostrar la relación de éstas con la moral, con la justicia, con el bien común, sería ininteligible por falto de sentido. El Derecho nos resultaría incomprensible si no lo pudiéramos poner en relación con los fines o valores que está llamado a realizar, que serían básicamente la promoción del bien común y de la justicia que están reconocidos en ese corpus mysticum del que habla Recaséns, tomando aquí este concepto de iusnaturalistas clásicos como Francisco Suárez, pues la validez del Derecho no se extiende más allá de los límites del grupo que lo integra.

Por todo lo dicho, no nos parece que esté de más esta reivindicación de Recaséns de esos valores, de esos principios de justicia que desempeñan un papel importante en la elección de cada persona individual, y su propuesta en la línea de un proyecto común igualitarista, pero dotado siempre de contenidos de justicia, lo cual nos va a resultar enormemente útil para entrar en el análisis y revisión que Recaséns hace del formalismo jurídico y su proyección en el krausismo.

20 Recaséns Siches, L., Tratado General de Filosofía del Derecho, 19. ${ }^{\circ}$ edición, editorial Porrúa, México, 2008 (primera edición, 1959), p. 7.

21 Ibid. 
De acuerdo con esta axiología jurídica, se produce así lo que podríamos considerar un revival del iusnaturalismo en este periodo de la Edad de Plata Española, también conocido como la «segunda escuela española de Derecho natural»; un momento en que los regeneracionistas vuelven su mirada hacia los escritores del Siglo de Oro para buscar en ellos, como exponentes de los ideales de la España anterior a un largo periodo de decadencia, estímulos y revulsivos para reformar la vida cultural y política en España. En el marco de esta lectura que hace el iusnaturalismo krausista decimonónico español de los clásicos hispanos, se encuadra perfectamente la obra de Recaséns, quien fue un gran conocedor del gran protagonismo cultural que tuvieron los miembros de la Escuela de Derecho Natural Española y, muy señeramente, de Francisco Suárez.

Ciertamente, Recaséns hizo una minuciosa y concienzuda lectura de la obra de Francisco Suárez, llegando a ser un experto en su doctrina, algo que plasmó en una magnífica obra titulada La Filosofía del Derecho de Francisco Suárez, con un estudio previo sobre sus antecedentes en la patrística y en la escolástica, que no es sino el fruto de su tesis doctoral (se publica en Barcelona en 1927 y se reedita en México en el año 1947)22, donde reflexiona sobre su implicación en episodios clave de la formación de la identidad moderna. Algo que, posteriormente, y pasado por el tamiz de la filosofía krausista donde la doctrina de Suárez conoce un nuevo desarrollo con una proyección en el pensamiento contemporáneo que alcanza hasta nuestros días, conserva su interés en el proceso de fundamentación de los valores del Estado de Derecho y donde, en efecto, encuentra su mejor realización práctica en todos los regímenes constitucionales de los países efectivamente civilizados. Por esta razón, la doctrina de Francisco Suárez que predica Recaséns sigue siendo familiar a la teoría jurídica y política del presente, que es eminentemente una teoría de la acción racional ${ }^{23}$.

Según expone Recaséns, para hablar de esta primera renovación que experimentó la Filosofía del Derecho en España desde finales del siglo XIX hasta el primer tercio del siglo XX, es preciso partir, sin duda, de la filosofía jurídica del krausismo español. En efecto, el krausismo actúo en España de poderoso agente modernizador político, educativo y social, hasta el punto de que fue una de las principales fuentes del renacimiento intelectual español y ello, por varias razones que señala el propio Recaséns Siches:

«En primer lugar, la filosofía krausista española mantuvo a un alto nivel los estudios filosófico-jurídicos, y ofreció una concepción iusnaturalista, en una época -último tercio del siglo XIX—en que tales cosas habían sido barridas por el positivismo en la mayor parte de áreas intelectuales. En segundo

22 Recaséns Siches, L., La Filosofía del Derecho de Francisco Suárez, con un estudio previo sobre sus antecedentes en la patrística y en la escolástica, Barcelona, $1^{a}$ edición 1927, cita por la $2^{\text {a }}$ edición corregida y aumentada, México, editorial jus, 1947.

23 Cfr. Pérez Luño, A.-E., La polémica sobre el nuevo mundo. Los clásicos españoles de la Filosofía del Derecho, Madrid, Editorial Trotta, Colección Estructuras y Procesos, Serie Derecho, 1992. 
lugar, el krausismo español fue no solamente un amplio e intenso movimiento filosófico, especialmente filosófico-jurídico, sino que fue además un importante factor real en la realidad de la política y del Derecho» ${ }^{24}$.

Como relata Recaséns, después del eclipse que la Filosofía del Derecho sufrió en los tres primeros decenios de la segunda mitad del siglo XIX por la acción de las corrientes positivistas, materialistas y evolucionistas, el pensamiento filosófico sobre lo jurídico empezaba a renacer en la mente de algunos esclarecidos jurisconsultos krausistas, señeramente y entre otros maestros krausistas e institucionistas, en Francisco Giner de los Ríos²5, quien en seguida sintió las limitaciones que sufría un positivismo legalista, que al centrarse en discursos descriptivos o meramente explicativos, cuando no puramente críticos de cualquier intento de legitimación del derecho, no dejaba lugar para un discurso propiamente justificativo, imposibilitando algo que es crucial para el iusnaturalismo que defienden tanto el krausismo como Recaséns: que se pueda dar cuenta del discurso interno del Derecho, de su relación con la moral, de su legitimación. Así Recaséns reconocía su labor al indicar que «Francisco Giner de los Ríos [...] fue la figura más eminente del movimiento krausista español, [...] y el más destacado filósofo del Derecho — sensu stricto - de su país en el siglo XIX y los inicios del XX, poseedor de una información completa y de un pensamiento en varios aspectos original» ${ }^{26}$.

En ese contexto se sitúan pues las obras de Francisco Giner, Adolfo Posada y de Joaquín Costa, junto con otros de los más representativos exponentes del krausismo español y del espíritu regeneracionista del 98, quienes mostraron tener una gran erudición sobre el pensamiento jurídico y político hispano del Siglo de Oro e hicieron notables aportaciones a este sector de la historiografía filosófico-jurídica.

Por ejemplo, Adolfo Posada impulsó este proceso reivindicativo de los iusnaturalistas clásicos hispanos y se empeñó por conjugarlo con el pensamiento ilustrado de la tradición krausista, en la convicción que ambos tenían por revalorizar el papel social y democrático de las instituciones políticas tradicionales hispanas. Baste considerar la amplia significación que para Francisco Giner tiene la idea de organismo, y su consideración de la Sociedad como un cuerpo social (que Posada trata de cifrar en la metáfora de la matriz organizativa del poder político del corpus mysticum suareciano),

24 Recaséns Siches, L., Panorama del pensamiento jurídico en el siglo XX, México, Editorial Porrua, primer tomo, 1. ${ }^{\mathrm{a}}$ ed., 1963, p. 11.

25 Las críticas de Giner contra las tesis inmovilistas a que abocaba el positivismo normativista más formalista se encuentran perfectamente desarrolladas y argumentadas en sus Principios de Derecho Natural y en los dos tomos de su Resumen de Filosofía del Derecho. Giner de los Ríos, F.; Calderón, A., Prolegómenos del derecho. Principios de derecho natural, Madrid, OO.CC., t. I, 1916, p. 58. Giner de los Ríos, F.; Calderón, A., Resumen de Filosofía del Derecho, Madrid, OO.CC., Tomo I, t. XIII y Tomo II, t. XIV, 1926, 323 pp.

26 Recaséns Siches, L., Panorama del pensamiento jurídico en el siglo XX, México, Editorial Porrua, primer tomo, 1. ${ }^{\mathrm{a}}$ ed., 1963, p. 12. 
donde la sociedad es un organismo moral del cual, conviene recordar, el Estado es tan sólo un órgano social más ${ }^{27}$. El propio Posada en su Tratado de Derecho Político se ocupa de esta dimensión ética del derecho que tiene su sede en la conciencia humana - en el hombre interior- hasta el Estado, donde su concepto de "fluido ético» adquiere un lugar central, a modo de "un reforzamiento "místico-metafísico" en el Posada de la madurez, que la enlaza, ante todo, con el pensamiento de F. Suárez, del "cuerpo místico", donde el hombre interior resulta ser el fundamento último del Derecho y del Estado "verdadera Ciudad de Dios" en la tierra, creada y sostenida por el esfuerzo del hombre ${ }^{28}$.

De modo semejante, krausistas como Giner hacen ver que el objetivo racional de la organización estatal es siempre más pobre que los valores a los cuales aspira y que realiza la comunidad subyacente de ese corpus mysticum suareciano que los krausistas tanto valoraron ${ }^{29}$. Con respecto a este tema, dice Adolfo Posada que este interés por recuperar la tradición de pensamiento de la Escuela Española de Derecho Natural para su época se despertó:

«al leer, de nuevo, en el gran infolio del P. Francisco Suárez S. J., en el tratado De Legibus ac Deo Legislatore, edición de 1613, puesto ahora en castellano por Torrubiano y Ripio, 1918, y —relata Adolfo Posada su interés-al comparar o relacionar algunos de los razonamientos y concepciones de aquel insigne pensador español, teólogo y filósofo de primera magnitud, uno de los magni hispani que estudia Kohler, con ciertas ideas capitales del maestro Francisco Giner, expuestas y explicadas éstas en algunos de sus libros, verbigracia, en sus estudios de Filosofía y Sociología y en varios de sus trabajos sobre La persona social» ${ }^{30}$.

27 Posada, A., «El "Cuerpo místico" del P. Suárez y el "Organismo social” del Maestro Giner», op. cit., p. 120.

28 Monereo Pérez, J. L., «El pensamiento político-jurídico de Adolfo Posada», en: Posada, A., Tratado de Derecho Político, op. cit., p. XXV.

29 Recuérdese aquí la importancia de diferenciar Estado y Gobierno en la teoría política krausista, que Giner expresa en términos afines a la teoría de los dos contratos de Suárez. Vid. Manzanero, D., «El fundamento democrático de la soberanía en Francisco Giner, según el Corpus Mysticum de Francisco Suárez», Isegoría. Revista de Filosofía Moral y Política, N. 53, julio-diciembre 2015, pp. 571-592, doi: 10.3989/isegoria.2015.053.06

30 Posada, A., "El "Cuerpo místico" del P. Suárez y el "Organismo social" del Maestro Giner», Boletín de la Institución Libre de Enseñanza [en adelante BILE], LII, tomo I, 1928, p. 118. Encontramos en este artículo de Posada un testimonio de estas relaciones entre las concepciones generales de la filosofía del derecho y sociología de Francisco Giner de los Ríos, con las ideas sobre el corpus mysticum de Suárez expresadas en el De Legibus, en las que el krausismo encuentra, de modo indirecto, también su raíz histórica y doctrinal. La recuperación de esta idea del corpus mysticum a la que Posada dedica su estudio, a la manera como lo expuso Francisco Suárez entre los escolásticos, vino principalmente de la mano de la noción de organicismo social y la caracterización de la sociedad hecha por la filosofía jurídica krausista, con un marcado carácter real y sustancial de las personas sociales ginerianas entendidas - a la manera del corpus mysticum suareciano- como corporaciones donde hay un consorcio de voluntades. El reconocimiento de personalidad a esas personas supraindividuales y la concesión de un papel vital en el desarrollo de la actividad humana resulta 
Ello se pone particularmente de manifiesto en su afán por hallar afinidades entre el pensamiento del filósofo y teólogo jesuita Francisco Suárez con el pensamiento de su maestro, Francisco Giner, quienes, en efecto, presentaban profundas afinidades en materia de sociología y de filosofía política, pues, según Posada, «Hállanse ambos filósofos [Suárez y Giner] —magni hispani-, cada cual a su modo y en su momento, dentro de una de las corrientes más constantes y constructivas de la historia del pensamiento, como ahora diríamos, "sociológico" y "político" $)^{31}$.

Resulta curioso también constatar cómo este fenómeno de recuperación del legado de nuestros clásicos hispanos de la Escuela de Derecho Natural, fue llevado a cabo, paradójicamente, no desde quienes se presentaban como tradicionalistas, sino desde las premisas reformadoras y liberales krausistas que auspiciaron una lectura renovadora, en clave liberal y democrática, de sus doctrinas.

Ese propósito determina que su revisión de los clásicos suponga una lectura interesada —en el mejor de los sentidos del término-y que, las más de las veces, se subordine su gusto por la erudición filológica y metafísica, a la intención pragmática que pretenden derivar de ese pensamiento hacia los problemas acuciantes del contexto ideológico del regeneracionismo de la España de finales del siglo XIX y principios del XX; por ejemplo, en su reivindicación de las libertades de los ciudadanos y de las personas sociales, de unos principios universales para el Derecho Internacional, la orientación de toda política al bien común, así como el derecho y el deber del pueblo a resistir la tiranía mediante la desobediencia a las leyes que son manifiestamente injustas, etc.; ideas todas ellas presentes en la filosofía jurídica de Francisco Suárez que vuelven a adquirir nueva vitalidad y a fortalecerse en la doctrina krausista, y cuyas consecuencias se van a proyectar en todos los aspectos de la vida cultural y política española.

En verdad, el krausismo fue el encargado de mantener la llama del iusnaturalismo y de la obra de Suárez en una segunda mitad de siglo XIX dominada por el positivismo científico y jurídico; una llama que, junto a la generación de Ortega y Gasset, llega también a alumbrar la obra de Recaséns Siches, quien no podía mantenerse al margen de este florecimiento cultural ${ }^{32}$.

plenamente coherente con la filosofía social krausista, incluso podemos decir que es un corolario lógico que encuentra su raíz en Krause, y un precedente esencial en Suárez, quienes hicieron posible a Giner construir una teoría sociopolítica bien conformada en este terreno.

31 Ibídem, pp. 118-119.

32 «Tras comparar el esplendor y la importancia del pensamiento alemán con el de la Antigua Grecia, pasa nuestro autor [Recaséns] a enumerar a los más importantes pensadores alemanes modernos (Kant, Leibniz, Fichte, Schelling, Hegel y Krause). Es especialmente significativo que Recaséns incluya a KRAUSE en esta apresurada lista. De hecho, el krausismo, en su vertiente institucionista, no dejará de ocupar un cierto lugar en su obra. De los tres "sociólogos sin sociedad" es, si no el más influido por el krausismo [...] el que más abiertamente valora y respeta aquél movimiento intelectual. Ribes LeIva, A. J., "Luis Recaséns Siches (19031977): la sociología como respuesta a la crisis, defensa del individuo y fundamentación de la convivencia», Anduli: Revista Andaluza de Ciencias Sociales, Núm. 5, 2005, p. 12. 
Recuérdese además que Recaséns participó en el proyecto krausista de renovar la ciencia española que, por aquel entonces, era cultivada mayoritariamente por los neoescolásticos, y de continuar la obra de Francisco Giner, esto es, permitir la importación de nuevas doctrinas jurídicas para que arraigaran en el suelo español. De hecho, Recaséns fue pensionado por la Junta para la Ampliación de Estudios e Investigaciones Científicas, la cual permitió a una multitud de jóvenes estudiar fuera de España para ir en busca de nuevas ideas iusfilosóficas europeas ${ }^{33}$. El contacto que mantiene Recaséns Siches con las principales universidades europeas no se entiende sin el importante rol que tuvo para su formación la JAE y su política de pensionados en el extranjero, gracias a la cual, fue becado para realizar estudios de Filosofía del Derecho, Filosofía General, Teoría General del Estado y Sociología en la Universidad de Berlín durante un año (1925-1926).

En virtud de estos proyectos culturales e iniciativas investigadoras, el iusnaturalismo quedaría restaurado años más tarde con éxito y amplia resonancia en España y en toda Europa, de ahí también la relevancia de esta estancia becada por la JAE en Alemania para la formación y el posterior decurso de la obra de Recaséns y de la iusfilosofía en España ${ }^{34}$.

\section{Actualidad DE SU MODERNA TEORÍA INTERPRETATIVA DEL DERECHO}

La filosofía jurídico-social de la Edad de Plata española no fue ajena a las investigaciones de los fenómenos sociales y creemos que también, en este aspecto de su filosofía, se encuentra un punto de anclaje interesante con la Escuela de Derecho Natural Española y, en particular, con su modelo interpretativo del derecho en la fórmula griega de la epiqueya. Una fórmula que los krausistas, como inmediatamente después Recaséns Siches, recuperaron de la doctrina de Francisco Suárez, quien no sólo llega a plantearse esta disputa entre un modelo más historicista y realista y otro modelo más abstracto e idealista, sino que

33 Fueron muchos los jóvenes iusfilósofos españoles a los que se les permitió, bajo el cobijo y orientación de la JAE, conocer la Filosofía del Derecho europea: «sépase también cuántos filósofos académicos del Derecho se beneficiaron entre 1907 y 1936 de las becas de la Junta, con las que pudieron irse al extranjero, sobre todo a Alemania, a estudiar junto a los pensadores más punteros de la especialidad: por lo menos, F. Rivera Pastor, B. Ramos Sobrino, L. Recaséns Siches, E. Luño Peña, L. Legaz Lacambra, J. Corts Grau o F. González Vicén». RivaYA, B., "Historia política de la filosofía del Derecho española del siglo XX», en: DOXA, Cuadernos de Filosofía del Derecho, 32, 2009, p. 545.

${ }_{34}$ Cuadros Aguilera, Pol, «Recaséns Siches y la renovación de la iusfilosofía en España», ponencia del I Congreso de Filosofía del Derecho para el mundo latino, Alicante, 26-28 de mayo de 2016, p. 10, Fecha de consulta (23-02-2017) iusfilosofiamundolatino. ua.es/download/Recas\%C3\%A9ns\%20Siches $\% 20 \mathrm{y} \% 20 \mathrm{la} \% 20$ renovaci\%C3\%B3n $\% 20 \mathrm{de} \% 20$ la $\% 20$ iusfilosof $\%$ C3\%ADa $\% 20$ en $\% 20$ Espa $\%$ C3\%B1a.\%20Pol\%20Cuadros\%20Aguilera. $\% 20$ Espa\%C3\%B1a..pdf 
brinda una de las más profundas soluciones armónicas de cuantas se han dado a este problema, al justificar la historicidad de una parte del Derecho natural de un modo más maduro y magistral que todos sus antecesores ${ }^{35}$.

No sería pues lícito olvidar que, precisamente, uno de los aspectos más encomiados de la obra de Francisco Suarez y, en general, de la Escuela española, en relación con los excesos acrónicos de la Escuela racionalista del Derecho natural, había sido precisamente el de su apertura a lo histórico y a los estudios de la sociología ${ }^{36}$. Por lo tanto, la explanación del concepto del Derecho en estos autores no se queda pues en una mera teoría idealista y esto es lo que hace de su doctrina un elemento claramente precursor y moderno en la filosofía de Suárez que será retomado por Recaséns Siches:

«estos magni hispani constituyen una fuente inagotable para la filosofía jurídica y brindan numerosos sugestiones para el progreso de la misma. En ellos el derecho natural no es un código rígido, siempre igual, e idéntico para todas partes. A pesar de sostener la invariabilidad del mismo (en cuanto al total de sus posibilidades), se presentan las normas ideales con un carácter movible y maleable, de modo que se adaptan siempre a las exigencias del momento [...] Para renovar el derecho natural — dice expresamente Kohler- es a ellos a quien debía cubrirse, y no a Hugo Grocio, bajo cuyo pensamiento perdió la doctrina iusnaturalista de los clásicos españoles todo su flexible aroma para quedar anquilosada en el hieratismo calvinista ${ }^{37}$.

Desde luego, con este planteamiento de Suárez, retomado por los intelectuales del krausismo y por Recaséns Siches, se propone un concepto de Derecho natural mucho más interesante que otros tipos de iusnaturalismos conservadores que se habían vivido en el siglo XX en España y que exhibían un formato más ortopédico, pues su forma de entender el Derecho natural no cae en esos excesos en que incurriría ese derecho natural cerrado y ahistórico, sino que advierte una progresiva inclinación de su filosofía iusnaturalista hacia aspectos sociológicos que le llevan a reflexionar sobre cuestiones prácticas.

Puede apreciarse la continuidad de este pensamiento de Suárez en la obra de Recaséns Siches. En efecto, para Recaséns, como para el que fue su mentor en Italia, Giorgio del Vecchio, el Derecho natural es esencialmente un método para descubrir lo justo, pero - y aquí radica la novedad de su pensamiento- «lo justo», en su opinión, se identifica, no en una realidad metafísica o teológica, sino en las relaciones sociales. No es algo que no se encuentre en las normas,

35 Elorduy, E., «La epiqueya en la sociedad cambiante (teoría de Suárez)», Anuario de filosofía del derecho, $\mathrm{N}^{\circ} 13,1967-1968$, pp. 229-254.

36 Norbert, H., «Sobre el Derecho Natural Racionalista y el Derecho Natural Actual», Anuario de Derechos Humanos. Nueva Época, Vol. 1 (2000), pp. 77-94.

37 Recaséns Siches, L., La Filosofía del Derecho de Francisco Suárez, con un estudio previo sobre sus antecedentes en la patrística y en la escolástica, Barcelona, $1^{\mathrm{a}}$ edición 1927, cita por la $2^{a}$ edición corregida y aumentada, México, editorial Jus, 1947, p. 113. 
sino en la propia realidad social. Puede verse claramente este matiz presente en el iusnaturalismo moderado de Luis Recaséns Siches, por ejemplo, cuando afirma que:

«Lo que no es admisible es que se piense en serio que esas normas ideales son auténtico Derecho. Son el norte y guía que los hombres deben adoptar en la elaboración de sus normas jurídicas. Ahora bien, Derecho propiamente lo son tan sólo esas normas fabricadas por los hombres para regir las relaciones sociales de una colectividad política en un cierto lugar y en una determinada época» ${ }^{38}$.

Aquí tenemos obviamente un elemento positivista en su teoría, al reconocer que las fuentes del derecho son sociales, que proceden de la convención entre los hombres y no de un plano divino o supra natural, lo cual viene a trazar una línea de separación entre Teología y Política bien interesante.

Sin embargo, Recasens Siches, como seguidor de Suárez y de la Escuela Española del Derecho Natural, añade a esta tesis una observación propia de un iusnaturalismo moderado, como es la idea de que: a la esencia de lo jurídico pertenecería no ya propiamente la justicia, sino la referencia intencional a la justicia. Con otras palabras, en la obra de Recasens hay un claro intento de no confundir las esferas del Derecho y la Moralidad, pero sí que reconoce esta intencionalidad, esta idealidad hacia la que todo Derecho debe propender; dicho con sus propias palabras:

«corresponde esencialmente al Derecho la intención de orientarse hacia la realización de unos valores, es decir, pertenece a la esencia misma del Derecho el pretender ser justo. Pero lo que pertenece a la esencia de lo jurídico es solamente esa intención de justicia y no su logrado cumplimiento» ${ }^{39}$.

Vemos pues cómo Recasens afirma en clave iusnaturalista esa relación deseable entre Derecho y Moral, aunque no siempre coincidan en la práctica social. Lo que busca Recaséns en el Derecho natural bien puede decirse que es, más que nada, una forma de realizar los valores de lo que luego se ha llamado el Estado constitucional; de ahí que el constitucionalismo haya sido denominado en ocasiones como una especie de neoiusnaturalismo ${ }^{40}$. Algo que, de hecho, ha tenido una clara continuidad, y que se encontraba ya en germen en muchas de las tesis de fondo que él había aprendido de la doctrina de Francisco Suárez y de los iusnaturalistas clásicos hispanos. Ciertamente, fue Recaséns Siches

38 Recaséns Siches, L., Tratado General de Filosofía del Derecho, 19. ${ }^{\circ}$ edición, editorial Porrúa, México, 2008 (primera edición, 1959), p. 159.

39 Ibid., p. 51.

40 «en la defensa de los derechos del hombre es donde mejor encontramos la modernidad de esta Escuela, y su aportación a la democracia junto con el principio de soberanía popular matizado, que encontramos en Suárez. En definitiva, es en la Escolástica española donde comienza a andar el camino que con el tiempo culminará en el Estado Constitucional». Navas Castillo, A.; Navas Castillo, F., Derecho constitucional: Estado Constitucional, Madrid, Librería-Editorial Dykinson, 2005, p. 54. 
quien luego dotó a estas tesis de un desarrollo magistral gracias al cual dicha doctrina ha tenido una validez que llega hasta nuestros días ${ }^{41}$.

En cualquier caso, lo que quedaba claro es que el iusnaturalismo no puede subsistir, o resurgir, como una tesis ontológica del Derecho al modo de la escolástica medieval que trataba de definir el ser del Derecho para derivar de ahí un deber ser. Sino que el Derecho Natural podría resurgir y sobrevivir hoy en día, en todo caso, como una teoría sobre la fundamentación del Derecho, como una deontología jurídica, en los términos en que fundamenta Recaséns Siches su concepto del derecho como intencionalidad; una Filosofía del Derecho capaz de descender directamente al campo de las derivaciones prácticas que ha tenido gran desarrollo posteriormente, pues el pensamiento jurídico de nuestros días se acerca de nuevo más a la vida real y trata de influir sobre ésta, tal y como deseaba Recaséns.

\section{Conclusión}

En resumen, puede afirmarse que la Filosofía del Derecho Natural suareciana que es retomada por los krausistas españoles y por Recaséns Siches, no queda pues circunscrita al mero estudio mecánico de las legislaciones positivas, y tampoco se pierde en la elucubración abstracta de un derecho natural, como si de una creación pura de la razón individual humana se tratara. Por el contrario, estos autores dirigen sus esfuerzos por elevar el nivel de los estudios jurídicos haciendo ver la índole práctica del derecho, ampliando los horizontes de esta ciencia, ya exponiendo el carácter sociológico del derecho y su íntima relación con la política y la moralidad, ya, en fin, haciendo notar la posibilidad de una aplicación razonada de los procedimientos positivos al estudio adecuado de los fenómenos jurídicos, que para Recaséns se presentan saturados de la vida social, y que tienen por necesidad un aspecto sociológico interesantísimo que a él no se le escapa.

Ello resulta particularmente relevante en el momento presente, en que el iusnaturalismo atomista rígidamente codificado de los siglos XVII y XVIII está obsoleto. Consideramos que una vuelta a la filosofía jurídico-social de los iusfilósofos clásicos puede procurar un plano de reflexión sobre el que debatir sobre los valores jurídicos y, en tal sentido, es interesante prestar atención a

${ }^{41}$ Véanse por ejemplo las tesis de un eminente constitucionalista alemán que también ha reflexionado sobre los valores en la interpretación jurídica, como Robert Alexy, y en el juez norteamericano Ronald Dworkin, los cuales han sido considerados como los dos principales representantes de la teoría constitucionalista del Derecho contemporánea. Saltan a la vista las similitudes entre muchas de las principales tesis defendidas por Alexy por las formulaciones de Recaséns Siches, donde éste parece anticipar en ocasiones un pensamiento casi idéntico y precursor a las ideas de Alexy. Vid. Cabra Apalategui, J. M., «Claves de la argumentación jurídica en Recaséns Siches, L.: estimativa jurídica y logos de lo razonable», Anuario de Filosofía del Derecho, 2011 (XXVII), pp. 37-61. 
las doctrinas jurídicas de Francisco Suárez, tal y como fueron recuperadas y revitalizadas en la Filosofía del Derecho del krausismo español, y en las profundas y enriquecedoras formas que adoptan los principales conceptos suarecianos en la obra de Recaséns Siches.

Ciertamente y, en líneas generales, puede afirmarse que la Filosofía del Derecho de hoy en día pone un mayor énfasis en que la razón debe servirse de orientaciones históricas y sociales; de ahí que Recaséns haga hincapié -recuperando así la fórmula suareciana- en que lo que es recto no lo puede fijar una razón abstracta, sino una razón práctica que se mueve en contextos históricos determinados y que se dirige a fines concretos:

«el jurista no debe pensar su caso in abstracto y lanzarse después a la norma aplicable a cada caso. Por el contrario, deber tener en cuenta las finalidades a las que trata de servir el orden jurídico positivo en vigor, esto es, en función de las valoraciones en que dicho orden jurídico positivo está efectivamente fundado» ${ }^{42}$.

Este es uno de los aspectos clave del iusnaturalismo clásico que mayor incidencia ha tenido transcurridos los siglos. En efecto, su proyección actual se ha visto más reforzada en aspectos clave como este de la Epiqueya suareciana, en el que los iusnaturalistas españoles supieron intuir y prescribir una apertura dialógica de los valores a lo histórico y a lo concreto, más que en otras afirmaciones tendentes a exaltar el carácter absoluto e inmutable de la ley natural ${ }^{43}$. La función que viene a cumplir el concepto y la práctica de la epiqueya demuestra la sensibilidad que tanto Suárez como Recaséns mostraron hacia lo concreto y su apertura a lo histórico, lo cual podría esgrimirse en defensa de la Filosofía del Derecho Natural en dichos autores.

En resumidas cuentas, lo que queremos hacer notar es que en esta defensa que hace Recaséns de una concepción flexible del Derecho natural fundamentada en la doctrina de Suárez, en algunos aspectos como este de la sociología y la interpretación razonable del Derecho, coincide con el moderno enfoque argumentativo del Derecho, encargado de clarificar el sentido y alcance de esa moralidad institucional a través de la interpretación. De hecho, diversos autores a los que puede considerarse entre los pioneros de la teoría contemporánea de la argumentación jurídica se han considerado a sí mismos,

42 Recaséns Siches, L., Tratado General de Filosofía del Derecho, 19. edición, editorial Porrúa, México, 2008 (primera edición, 1959), p. 3.

43 Recaséns publica su voluminoso Tratado general de Sociología en, México, Porrúa, 1956 , libro que tuvo un gran impacto internacional y que ha conocido numerosas reediciones y reimpresiones. A este respecto, es importante recordar que Recaséns mantuvo en España el interés por la Sociología y que aplicó con gran dedicación tales conocimientos sociológicos a su doctrina filosófica, a pesar de encontrarse en un ambiente claramente hostil en el que se miraba con recelo a esta nueva ciencia social empírica que - en la perspectiva de los sectores más tradicionalistas obcecados en mantener unos criterios periclitados- amenazaba con arrumbar creencias religiosas y con minar el normativismo clásico iusnaturalista vigente en la academia. 
con mayor o menor intensidad, como autores iusnaturalistas ${ }^{44}$. La concepción de base iusnaturalista suareciana en la obra de Recaséns, en tanto en cuanto defiende una concepción del razonamiento jurídico contrapuesta a la de la lógica formal deductiva, sería pues uno de los precursores más destacados de las teorías contemporáneas de la argumentación jurídica.

En definitiva, la vigencia actual de la doctrina de Francisco Suárez y del iusnaturalismo clásico español dependerá de la propia posibilidad de una lectura en clave contemporánea de sus tesis; de reconvertir su concepción metafísica en una crítica y orientación del presente que responda a las provocaciones del momento histórico que vivimos. Por esta razón, consideramos que en la actual coyuntura filosófico-jurídica, abierta al reconocimiento de la competencia práctica de la razón, sirve para establecer pautas éticas fundamentadoras de una convivencia social justa, donde la doctrina de clásicos iusnaturalistas hispanos como Francisco Suárez sigue representando un provechoso estímulo.

Universidad Rey Juan Carlos de Madrid

Delia Manzanero

delia.manzanero@urjc.es

[Artículo aprobado para publicación en enero de 2018]

44 Es evidente que el ropaje conceptual y los presupuestos teóricos de estos nuevos iusnaturalismos difieren notablemente de los planteamientos iusnaturalistas de los clásicos, pero su actitud frente al Derecho, y la necesaria referencia a pautas morales y de justicia que trascienden la positividad, presentan numerosos puntos de entronque. Cfr. Atienza, M., El derecho como argumentación, Barcelona, Ariel, 2006, 316 pp. 